\title{
Comparison of Two Different Doses of Dexamethasone to Control Swelling and Trismus following Mandibular Third Molar Surgery
}

\author{
Pranay Ratna Sakya, ${ }^{1}$ Dipti Shrestha, ${ }^{1}$ Reena Shrestha, ${ }^{1}$ Dhiraj Khadka, ${ }^{1}$ \\ Ratina Tamrakar, ${ }^{2}$ Sudeep Acharya ${ }^{3}$ \\ ${ }^{1}$ Department of Oral and Maxillofacial Surgery, Peoples Dental College and Hospital, Sorahkhutte, Kathmandu, Nepal; \\ ${ }^{2}$ Dental Unit, Oral and Maxillofacial Surgery, Nidan Hospital, Phulchowk, Lalitpur, Nepal; \\ ${ }^{3}$ Oral and Maxillofacial Surgeon, B.P Eye foundation, Bhaktapur, Nepal.
}

\begin{abstract}
Introduction: Third molar surgery is one of the most common procedure performed by dental surgeons in clinical practice, where postoperative sequelae like pain, trismus and swelling is often encountered. Thus, in this study we compared medications employed to reduce such complications.

Objective: To compare the effect of two different doses (4 and $8 \mathrm{mg}$ ) of dexamethasone in the control of swelling and trismus after the surgical extraction of mandibular impacted third molars.

Methods: An experimental study consisted of twenty-seven (27) healthy adult patients of both genders with bilateral impacted lower third molars, where surgical extraction was indicated, $4 \mathrm{mg}$ and $8 \mathrm{mg}$ of dexamethasone were given orally to the patients 1 hour before the surgical procedure at both the surgeries. Swelling was recorded by measuring the length of 3 facial planes using measuring tape. Trismus was evaluated by measuring the maximum interincisal distance. Recording of facial swelling and maximum interincisal distance was done preoperatively, and on 1st and 2nd day postoperatively.

Results: Based on statistical analysis (Independent T test), the results showed a difference in the measurements of the degree of swelling and trismus of the treated sample. $8 \mathrm{mg}$ of dexamethasone promoted a greater reduction of symptoms than $4 \mathrm{mg}$ of dexamethasone though there was no statistically significant ( $p$ value $>0.05$ ) difference between the two doses.

Conclusions: 8 milligram of the dexamethasone had better effectiveness than 4 milligram of the dexamethasone in reducing the degree of swelling and trismus.

Keywords: Dexamethasone; impacted third molars; swelling; trismus.
\end{abstract}

\section{INTRODUCTION}

Surgical extraction of impacted third molars is a common procedure performed in oral and maxillofacial surgery. ${ }^{1}$ Pain, trismus and swelling are the most common postoperative sequelae following surgical extraction of impacted third molar whose

Correspondence
Dr.Pranay Ratna Sakya
Email : drpranaysakya@gmail.com
Citation
Sakya PR, Shrestha D, Shrestha R, Khadka D, Tamrakar R,
Acharya S. Comparison of Two Different Doses of Dexamethasone
to Control Swelling and Trismus following Mandibular Third
Molar Surgery. Nepal J Health Sci. 2021 Jul-Dec;1(2):1-6.

occurrence is related to local inflammatory reaction, with prostaglandins and cyclooxygenase having a major role. Although proper surgical technique and tissue handling can minimize these sequelae, cannot prevent them completely. ${ }^{2}$

Various approaches like drains, laser therapy, drugs like enzymes, muscle relaxants have been used to minimize these complications. ${ }^{1}$

Studies have shown corticosteroids to be effective in reducing inflammatory sequelae following surgical extraction of impacted mandibular third molar. ${ }^{2}$ Corticosteroids act by inhibiting the enzyme Phospholipase A2, which leads to decrease in release 
of arachidonic acid in the inflamed tissue, thereby inhibiting the synthesis of inflammatory mediators like prostaglandins and leukotrienes, which are responsible for inflammatory symptoms like pain, swelling and trismus. Corticosteroids also reduce the release of inflammatory lysozymes, and reduce diapedesis by decreasing membrane permeability. 3,4

Dexamethasone, a synthetic analogue of methylprednisolone, has 5-10 times antiinflammatory effect as prednisone and prednisolone, and 30 times that of cortisone. ${ }^{1}$ Studies have shown the use of different doses of dexamethasone without actually comparing them..$^{3-5}$

Therefore, this study aims to compare the effectiveness of two different dosage of Dexamethasone in controlling postoperative inflammatory sequelae following mandibular third molar surgery.

\section{METHODS}

A prospective, randomized, controlled, blind, parallel-group design study was performed with the approval of the Institutional Review Committee of Peoples Dental College and Hospital Kathmandu, Nepal with Ref no.1. CH No 26. 2077/78. The surgical and experimental procedures were explained verbally and in writing, and informed consent was obtained before enrolment. Sample size was calculated using the values from reference article Laureano Filho JR, Maurette PE, Allais M, Cotinho M, Fernandes C. ${ }^{6}$ A total of twenty-Seven (27) patients with impacted lower third molars, between 18 and 45 years visiting Peoples Dental College and Hospital from July 2021 to August 2021(two months) were operated by the same oral surgeon following same surgical protocols and techniques.

A complete medical history was taken and an oral examination was performed, panoramic radiograph was taken to confirm the need for third molar removal. Patients were allotted to receive either 4 $\mathrm{mg}$ or $8 \mathrm{mg}$ of dexamethasone 1 hour preoperatively during the first surgery using lottery system. Prior to extraction of impacted mandibular third molar on one side, patients were asked to draw a chit from the box, and they were assigned to the group they drew. For extraction of impacted mandibular third molar of the opposite side, the patients were crossed over to the other group. The second surgery was planned after 15 days following the first surgery. For standardization of the sample, we used the following clinical criteria: 1) age between 18 to 45 years, 2) bilateral impacted mandibular third molars with either mesioangular or horizontal positions (Winter's classification), 3) equivalent degree of surgical difficulty comparing one side with the other, 4) no use of medication that could interfere with the healing process, and 5) no systemic disease. During the preoperative period, all patients had clinical adradiological evaluations. Prior to commencement of the surgical procedure, the patients were administered either $4 \mathrm{mg}$ or $8 \mathrm{mg}$ of tablet dexamethasone orally 1 hour preoperatively according to the chits they pulled out. The surgical site was prepared after rinsing with Povidone iodine $(5 \% \mathrm{w} / \mathrm{v})$ and the patients were draped in conventional manner. Inferior alveolar nerve block and terminal infiltration of buccal fold was performed by using a solution $2 \%$ Lignocaine hydrochloride with 1:80,000 Adrenaline. An envelope mucoperiosteal flap was raised. Bone removal using micromotor and carbide bur under constant irrigation was done. Tooth section was done whenever required. Tooth was luxated using straight elevators and then extraction was done with molar forceps if required. Closure was done with 3-0 silk suture.

Same post extraction instructions were given for both the groups and the medicines prescribed (Amoxicillin $500 \mathrm{mg} 8$ hourly for 5 days, Metronidazole 400mg 8 hourly for 3 days and Ibuprofen 400mg + Paracetamol 500mg combination 8 hourly for 3 days). Recording of swelling and mouth opening was done preoperatively. The patients were recalled on 1 st and 2nd post-operative days for recording swelling and mouth opening. Preoperative and 
postoperative recording of swelling and mouth opening was done by the evaluator who was unaware of the drug the subject was taking. Mouth opening was recorded by measuring the maximum interincisal distance (distance between the incisal edges of upper and lower central incisor) using a Vernier caliper. Swelling was assessed by measuring facial dimensions using Al-Shamiri H.M. , Shawky M. and Hassanein N. method which uses measurement in three planes using tape. ${ }^{1}$ The planes are: a) First plane: from tragus of ear to corner of mouth, b) Second plane: from gonion to corner of mouth, c) Third plane: outer canthus of the eye to the gonion.

Data collected was entered in Microsoft Office Excel sheet. Analysis of the data was done using Statistical Package of Social Sciences (SPSS) version 24 . The data was summarized to mean and standard deviation and was compared using t test.

\section{RESULTS}

The mean age of total of 27 patients who came for third molar extraction was 28.7 years with maximum age being 45 years and minimum being 20 years. The sex wise distribution showed that majority of the patients were female $(59.3 \%)$. (Table 1)
In the current study, the most common type of third molar impaction which was operated was mesioangular (88.9\%) followed by horizontal $(11.1 \%)$.

The mouth opening between both the groups at different time intervals were compared. Results showed that there was no significant difference in the interincisal distance between both the groups preoperatively. In the post-operative day 1 , the mean interincisal distance was higher among patients who received dexamethasone $8 \mathrm{mg}$ compared to patients receiving dexamethasone $4 \mathrm{mg}$. The same finding was recorded on post-operative day 2 as well, but the difference in measurements failed to reach statistical significance. Thus, this study showed that both the doses of dexamethasone have similar effect in reducing postoperative trismus when followed till day 2. (Table 2)

The extra oral swelling measurements measured in three different planes and total sum values at different time intervals were compared between both the groups. Results showed that there was no significant difference in the different measurements between both the groups preoperatively thus; patients in both the study groups were comparable before the intervention of the study. In the post-

Table 1: Age and sex distribution of the participants in the current study $(n=27)$.

\begin{tabular}{|l|l|c|}
\hline \multicolumn{1}{|c|}{ Variables } & \multicolumn{1}{|c|}{ Characteristics } & Descriptive statistics \\
\hline \multirow{4}{*}{ Age (in years) } & Mean \pm sd & $28.7 \pm 7.025$ \\
\cline { 2 - 3 } & Minimum value & 20 \\
\cline { 2 - 3 } & Maximum value & 45 \\
\hline \multirow{2}{*}{ Sex } & Male (n, \%) & $11(40.7 \%)$ \\
\cline { 2 - 3 } & Female (n, \%) & $16(59.3 \%)$ \\
\hline
\end{tabular}

Table 2: Comparison of maximum interincisal distance between both the groups at different time intervals $(n=54)$.

\begin{tabular}{|c|c|c|c|c|c|c|}
\hline \multirow{2}{*}{$\begin{array}{l}\text { Interincisal } \\
\text { distance }\end{array}$} & \multirow{2}{*}{$\begin{array}{c}\text { Dexamethasone } \\
\qquad \mathbf{8} \text { mg } \\
\text { (Mean } \pm \text { sd) }\end{array}$} & \multirow{2}{*}{$\begin{array}{c}\text { Dexamethasone } \\
4 \mathrm{mg} \\
\text { (Mean } \pm \text { sd) }\end{array}$} & \multirow{2}{*}{$\begin{array}{l}\text { Mean } \\
\text { diff. }\end{array}$} & \multicolumn{2}{|c|}{$95 \%$ CI } & \multirow[b]{2}{*}{ P value } \\
\hline & & & & Lower & Upper & \\
\hline Pre-operative & $45.06 \pm 6.96$ & $44.84 \pm 6.89$ & 0.224 & -3.560 & 4.009 & 0.906 \\
\hline Post-operative Day 1 & $43.08 \pm 7.61$ & $42.68 \pm 7.37$ & 0.395 & -3.697 & 4.487 & 0.847 \\
\hline Post-operative Day 2 & $40.53 \pm 8.92$ & $40.38 \pm 8.78$ & 0.153 & -4.682 & 4.989 & 0.950 \\
\hline
\end{tabular}


Table 3: Comparison of extra oral swelling measurements between both the groups at different time intervals $(n=54)$.

\begin{tabular}{|c|c|c|c|c|c|c|}
\hline \multirow[b]{2}{*}{ Interincisal distance } & \multirow{2}{*}{$\begin{array}{c}\text { Dexamethasone } \\
8 \mathrm{mg} \\
\text { (Mean } \pm \text { sd) }\end{array}$} & \multirow{2}{*}{$\begin{array}{c}\text { Dexamethasone } \\
4 \mathrm{mg} \\
\text { (Mean } \pm \mathrm{sd})\end{array}$} & \multirow[b]{2}{*}{$\begin{array}{c}\text { Mean } \\
\text { diff. }\end{array}$} & \multicolumn{2}{|c|}{$95 \% \mathrm{CI}$} & \multirow[b]{2}{*}{ P value } \\
\hline & & & & Lower & Upper & \\
\hline \multicolumn{7}{|c|}{ Distance from Tragus of ear to Gonion } \\
\hline Pre-operative & $114.78 \pm 5.56$ & $114.41 \pm 5.68$ & 0.370 & -2.702 & 3.442 & 0.810 \\
\hline Post-operative Day 1 & $115.48 \pm 5.13$ & $116.15 \pm 5.16$ & -0.667 & -3.480 & 2.147 & 0.636 \\
\hline Post-operative Day 2 & $116.22 \pm 5.45$ & $117.85 \pm 5.46$ & -1.630 & -4.610 & 1.350 & 0.278 \\
\hline \multicolumn{7}{|c|}{ Distance from Gonion to Corner of Mouth } \\
\hline Pre-operative & $90.96 \pm 9.42$ & $90.41 \pm 9.43$ & -0.679 & -3.602 & 2.245 & 0.646 \\
\hline Post-operative Day 1 & $92.11 \pm 8.85$ & $92.37 \pm 8.94$ & -2.446 & -5.243 & 0.350 & 0.086 \\
\hline Post-operative Day 2 & $93.37 \pm 8.89$ & $94.26 \pm 8.74$ & -1.589 & -4.316 & 1.138 & 0.251 \\
\hline \multicolumn{7}{|c|}{ Distance from Outer Canthus of the eye to the Gonion } \\
\hline Pre-operative & $108.37 \pm 6.84$ & $107.93 \pm 7.31$ & 0.444 & -3.425 & 4.314 & 0.819 \\
\hline Post-operative Day 1 & $108.44 \pm 6.33$ & $108.70 \pm 6.65$ & -0.259 & -3.807 & 3.288 & 0.884 \\
\hline Post-operative Day 2 & $108.48 \pm 6.09$ & $109.33 \pm 6.59$ & -0.852 & -4.318 & 2.614 & 0.624 \\
\hline \multicolumn{7}{|c|}{ Sum of measurements of all 3 planes } \\
\hline Pre-operative & $314.11 \pm 18.76$ & $312.74 \pm 15.42$ & 1.370 & -8.009 & 10.749 & 0.771 \\
\hline Post-operative Day 1 & $316.04 \pm 17.68$ & $317.22 \pm 14.15$ & -1.185 & -9.932 & 7.562 & 0.787 \\
\hline Post-operative Day 2 & $318.07 \pm 18.12$ & $321.44 \pm 13.32$ & -3.370 & -12.07 & 5.317 & 0.440 \\
\hline
\end{tabular}

operative day 1 and day 2, the mean measurements in all the three planes and as well as the sum total measurement of patients receiving dexamethasone $8 \mathrm{mg}$ was lower than the patients receiving dexamethasone $4 \mathrm{mg}$. This gives hint that patients receiving dexamethasone $8 \mathrm{mg}$ might have less swelling compared to patients receiving dose of 4 mg. However, the mean difference between the groups failed to reach statistical significance with $\mathrm{p}$ value $>0.05$. (Table 3 )

\section{DISCUSSION}

Third molar extraction is a well-accepted model used to evaluate the clinical efficacy of anti-inflammatory drugs. This model is characterized by localized pain that is predictable in character, duration (3-5 days), and intensity (moderate to severe). ${ }^{6}$

This study was designed to compare the clinical efficacy of dexamethasone of doses $4 \mathrm{mg}$ and $8 \mathrm{mg}$, which was administered 1 hour before the lower third molar was surgical extraction under local anesthesia.
In total, 27 patients requiring surgical extraction of impacted lower third molar bilaterally, were treated (one of the surgical extraction was assigned to group I and next operation in the same patient was assigned to group II). The sex wise distribution showed that majority of the patients were female $(59.3 \%)$. The female-to-male gender ratio in the present study was almost 3:2, which is in agreement with a previous study reporting that women seek third molar surgery more frequently than men. ${ }^{7}$ No eventful healing and postoperative complications were reported in any of the studied groups. To prevent the common side effects of steroids, a PPI drug was prescribed to some of the patients.

As stated in the literature, the degree of difficulty of the surgical procedure and the local trauma caused by the surgery varied among the patients. ${ }^{8}$ To eliminate this variability, patients requiring surgical removal of bilaterally impacted lower third molars were included in the study. A single operator was assigned to perform all the surgeries. The surgeon's differences in the skill and technique have been 
quoted as a cofounding factor for the surgical trauma and the subsequent complications. ${ }^{9}$

The method employed in this study to measure trismus and swelling is taken from the literature. ${ }^{10}$ benefits of this method lie in its simplicity. It is noninvasive, cost effective, time saving, and provides numeric data for the determination of trismus and soft-tissue contour changes.

From the present study, statistically, there is no significant difference in trismus and swelling between the two groups on the $1^{\text {st }}$ post-operative day as compared to the significant difference on $2^{\text {nd }}$ postoperative day.

Glucocorticoids potently suppress inflammation, and their use in a variety of inflammatory and autoimmune diseases makes them among the most frequently prescribed classes of drugs.

Use of the corticosteroid, dexamethasone either preoperatively, perioperatively, or postoperatively appears to be effective in the prevention of postoperative edema. ${ }^{10-12}$
Although dexamethasone has been reported to have gastrointestinal irritation, none of our subjects reported of any gastrointestinal irritation. Hence, it can be concluded that dexamethasone is safe for short term use for preventing acute postoperative swelling and trismus after surgical extraction in dentistry. Adverse effects with a single dose of dexamethasone are probably extremely rare and minor in nature, and previous studies have demonstrated that short-term (less than 24 hours) use of dexamethasone is safe. ${ }^{13}$

\section{CONCLUSIONS}

In this study it was observed that $8 \mathrm{mg}$ dexamethasone although not statistically significant showed better control of postoperative complications following mandibular third molar surgery. Therefore, a study with a larger sample size and longer follow up period is warranted to come to a definite conclusion.

\section{Conflict of Interest: None}

\section{REFERENCES}

1. Ngeow WC, Lim D. Do Corticosteroids Still Have a Role in the Management of Third Molar Surgery? Adv Ther. 2016 Jul;33(7):1105-39. doi: 10.1007/s12325016-0357-y. Epub 2016 Jun 10. PMID: 27287853; PMCID: PMC4939150.

2. Chopra D, Rehan HS, Mehra P, Kakkar AK. A randomized, double-blind, placebo-controlled study comparing the efficacy and safety of paracetamol, serratiopeptidase, ibuprofen and betamethasone using the dental impaction pain model. Int J Oral Maxillofac Surg. 2009 Apr;38(4):350-5. doi: 10.1016/j. ijom.2008.12.013. Epub 2009 Jan 24. PMID: 19168326.

3. Messer EJ, Keller JJ. The use of intraoral dexamethasone after extraction of mandibular third molars. Oral Surg Oral Med Oral Pathol. 1975 Nov;40(5):594-8 doi: 10.1016/0030-4220(75)90369-2. PMID: 1059060

4. Olstad OA, Skjelbred P. Comparison of the analgesic effect of a corticosteroid and paracetamol in patients with pain after oral surgery. Br J Clin Pharmacol. 1986 Oct;22(4):437-42. doi: 10.1111/j.1365-2125.1986.tb02914.x. PMID: 3533126; PMCID: PMC1401164

5. Skjelbred P, Løkken P. Post-operative pain and inflammatory reaction reduced by injection of a corticosteroid. A controlled trial in bilateral oral surgery. Eur Clin Pharmacol. 1982;21(5):391-6. doi: 10.1007/BF00542325. PMID: 7042372.

6. Laureano Filho JR, Maurette PE, Allais M, Cotinho M, Fernandes C. Clinical comparative study of the effectiveness of two dosages of Dexamethasone to control postoperative swelling, trismus and pain after the surgical extraction of mandibular impacted third molars. Med Oral Patol Oral Cir Bucal. 2008 Feb 1;13(2):E129-32. PMID: 18223530.

7. Averbuch M, Katzper M. Baseline pain and response to analgesic medications in the postsurgery dental pain model. J Clin Pharmacol. 2000 Feb;40(2):133-7. doi: 10.1177/00912700022008775. PMID: 10664918 .

8. Carvalho RW, do Egito Vasconcelos BC. Assessment of factors associated with surgical difficulty during removal of impacted lower third molars. J Ora Maxillofac Surg. 2011 Nov;69(11):2714-21. doi: 10.1016/j.joms.2011.02.097. Epub 2011 Jul 12. PMID: 21752507.

9. Trindade PA, Giglio FP, Colombini-Ishikiriama BL, Calvo AM, Modena KC, Ribeiro DA, Dionísio TJ, Brozoski DT, Lauris JR, Faria FA, Santos CF. Comparison of oral versus sublingual piroxicam during postoperative pain management after lower third molar extraction. Int J Oral Maxillofac Surg. 2011 Mar;40(3):292-7. doi: 10.1016/j.ijom.2010.10.026. Epub 2010 Dec 8. PMID: 21144709

10. Baxendale BR, Vater M, Lavery KM. Dexamethasone reduces pain and swelling following extraction of third molar teeth. Anaesthesia. 1993 Nov;48(11):961-4 doi: 10.1111/j.1365-2044.1993.tb07474.x. PMID: 8250191. 